\title{
Traditional acupuncturists and higher education in Britain: the dual, paradoxical impact of biomedical alignment on the holistic view
}

\section{Abstract}

Traditional acupuncturists' quest for external legitimacy in Britain involves the standardization of their knowledge bases through the development of training schools and syllabi, formal educational structures, and, since the 1990s, the teaching of undergraduate courses within (or validated by) Higher Education Institutions (HEls), a process which entails biomedical alignment of the curriculum. However, as holistic discourses were commonly used as a rhetorical strategy by CAM practitioners to distance themselves from biomedicine and as a source of public appeal, this 'mainstreaming' process evoked practitioners' concerns that their holistic claims are being compromised. An additional challenge is being posed by a group of academics and scientists in Britain who launched an attack on CAM courses taught in HEls, accusing them of being 'unscientific' and 'non-academic' in nature. This paper explores the negotiation of all these challenges during the formalization of traditional acupuncture education in Britain, with a particular focus on the role of HEls. The in-depth qualitative investigation draws on several data sets: participant observation in a university validated acupuncture course; in-depth interviews; and documentary analysis. The findings show how, as part of the formalization process, acupuncturists in Britain (re)negotiate their holistic, anti-reductionist discourses and claims in relation to contemporary societal, political and cultural forces. Moreover, the teaching and validation of acupuncture courses by HEls may contribute to broadening acupuncturists' 'holistic awareness' of societal and cultural influences on individuals' and communities' ill-health. This investigation reveals the dynamic and context-specific (rather than fixed and essentialized) nature of acupuncture practice and knowledge.

Keywords: Britain, Complementary and Alternative Medicine, Higher Education, acupuncture, biomedicine, holism, professionalization 
Introduction

Various studies have portrayed Complementary and Alternative Medicine (CAM) therapies' quest for external legitimacy via 'mainstreaming' strategies, such as the codification of their knowledge bases through the development of training schools and syllabi, the production of formal guidelines, accreditation procedures, and disciplinary mechanisms (see for example: Barnes, 2003 and Flesch, 2013 in the US; Shahjahan, 2004 in Canada; Shuval and Averbuch, 2012 in Israel; and Cant, 2009, Clarke et al., 2004, Saks, 2001 in Britain).This process, often discussed in the context of social closure by which professional privilege is guarded by restricting other groups from accessing resources or rewards, involves a degree of 'biomedical alignment', i.e. increasing the teaching of biomedical content and biomedical research methods as part of CAM training and education (Cant, 2009; Gale, 2014; Saks, 2001). For example, in discussing the knowledge claims of acupuncturists, homeopaths and naturopaths in Ontario as a way of determining jurisdictional boundaries, Welsh, Kelner, Wellman and Boon (2004) suggested that those groups that are seen to 'biomedically-align' their knowledge claims most, have the greatest chance of gaining social closure.

Since the 1960s, CAM practitioners adopted a holistic/'anti-reductionist' rhetorical strategy which overlapped with the holistic health movement and mirrored the counter-culture critique of biomedicine (Rosenberg, 1998; Saks, 2001). However, the later attempts to 'mainstream' CAM presented significant challenge to practitioners' claims for holism as well as for the indeterminacy and intuitive/artistic emphasis 
inherent in their practices (Clarke et al., 2004; Givati, 2015; Hirschkorn, 2006; Welsh et al., 2004). Moreover, as pointed out by Barnes (2003) in relation to acupuncture in the US, practitioners found themselves adhering to an educational system which has an increasing resemblance to that of medical and allied medical professions.

The dynamic nature of the holistic discourse in CAM

While discourses of holism are central to most CAM therapies (Fadlon, 2004; Keshet, 2009; Shuval \& Averbuch, 2012), holism in CAM is not a fixed, 'essentialised' term, and holistic discourses vary in relation to settings, audiences and circumstances (Givati, 2015). Notions of holism are commonly discussed as a number of interrelated concepts: the 'whole person' view and the interconnectedness between body, mind, emotions and spirit in the social context; recognising the important interaction between biology and culture in shaping 'who we are'; an increased patient empowerment and patient engagement in the therapeutic act/encounter; and the notion of vitality (Fadlon, 2004; Scott, 1999; Shuval \& Averbuch, 2012).

However, it is necessary to clarify a number of important issues in relation to CAM's holistic discourse. First, in light of the fluid and dynamic nature of practitioners' holistic claims, we avoid any static definition of holism. Rather, we would like to point at CAM practitioners' strategic utilisation of holistic claims and discourses as a professional resource, which are adaptable in relation to audiences and circumstances (Givati, 2015). Second, in light of the complex historical and political 
nature of the relationship between CAM and biomedicine, and 'given the remarkable complexities of the therapeutic act' (Bates, 2002, p.14), a certain degree of

dichotomy is unavoidable. It is not our intention, however, to argue that biomedicine is purely 'reductionist' or 'un-holistic' while CAM is the exact opposite. In fact, the debate over holism and reductionism was part of biomedicine long before the 1960s medical counter-culture (Lawrence and Weisz, 1998) and is integral to contemporary medical and allied to medical education and practice (Hasegawa, Reilly, Mercer, \& Bikker, 2005; Hill, 2003; Rosenberg, 1998). Moreover, in relation to the practice of acupuncture, whilst Chinese medicine and biomedicine are often presented as two discrete and competing medical systems, historical and ethnographic literature point to the ongoing cross-fertilisation between the two frameworks whereby practices and knowledge are adopted, integrated or appropriated in a process of two-way diffusion in relation to societal, political, medical and emotional needs (Barnes, 2005; Bivins, 2001; Scheid, 2002).

Moreover, there seems to be a clear gap between CAM practitioners' passionate claim for holism within the realm of individual responsibility and individual behaviours and the simultaneous lack of awareness for what Scott (1999) labelled as 'wider world' holism, i.e. recognising broader socio-political influences on health. This arguably leaves CAM practitioners with limited holistic narrative. The presentation of 'CAM's holism' versus 'biomedicine's reductionism' was critiqued by a number of scholars (Baer, 2003; Baer, Hays, McCLendon, McGoldrick, \& Vespucci, 1998; Crawford, 2006; Lowenberg \& Davis 1994; Montgomery, 1993; Scott, 1999) which argued that CAM practitioners' focus on individual behaviour and personal responsibility for health encourages 'victim-blaming' while failing to consider broader 
socio-political aetiologies such as living and occupational conditions or socioeconomic inequalities.

The dynamic, ever-evolving and 'holistically-diverse' nature of traditional acupuncture

Acupuncture is a broad, dynamic and diverse field of practice (Scheid, 2002), which is reflected in its large number of theoretical models and practice styles. However, in the Peoples' Republic of China (PRC), as part of the nationalisation of Chinese medicine, acupuncture underwent a process of institutionalization and 'streamlining'. This process involved the removing of older tests and practices that were deemed 'superstitious' or religious in nature (Barnes, 2003). As Barnes (ibid) points out, many of the first European Americans who came to China to study Chinese medicine studied the systemized and politicized version of the PRC, known as 'Traditional Chinese Medicine (TCM)'. One exception was an Englishman named Worsely, who, studied in the Far East during the 1950s and 1960s and 'imported' the 'Five Elements' acupuncture, a school of practice that became an immense influence on the development of acupuncture in Britain and the US. Broadly speaking, compared to TCM, the 'Five Elements' school of practice claims to have a greater orientation to the emotional and spiritual nature of practice. In contrast, 'Five Element' acupuncture is challenged by some practitioner-groups as neglecting the more 'technical-physical' perspective of acupuncture practice (for a discussion of 'Five Elements' acupuncture see Connelly, 1979). 
For example, on its website, one of the leading Chinese medicine schools in Britain describes TCM acupuncture as 'concentrating on the symptoms of a patient's illness' and 'as an effective framework for treating complaints', while suggesting that the 'five elements constitutional acupuncture [practice style] focuses on the person who has the illness, rather than the illness itself'. Another leading Chinese medicine school, on its website, describes TCM acupuncture as 'a reductionist [our emphasis] approach to simplify what can be observed in ill health and offer a direct remedy', while the 'Stems and Branches' style is described as being 'about transformations and interactions of qi that affects a person both internally and externally', rooted in the way 'the ancient Chinese' viewed the world as 'a holistic world [whereby] everything in the universe is connected'.

Each of the English schools accredited by the largest professional body of traditional acupuncturists, the British Acupuncture Council (BAcC), adopted and teaches somewhat different acupuncture style. Although 'Five Elements' practitioners often argue that TCM is too narrowly focused on symptoms as opposed to their more 'constitutional' practice (Barnes, 2005), schools commonly teach a synthesis of both approaches. Other popular traditional acupuncture modalities taught by accredited schools are 'stems and branches', which finds its theoretical roots in the cosmological Daoism, and Japanese meridian acupuncture.

Acupuncture and Higher Education in Britain

The process of standardizing acupuncture education in the UK started in 1980, following the unification of a number of disparate associations, with the aim to 
overcome the divisions of the varying practice traditions. A decade later, the British Acupuncture Accreditation Board (BAAB) was established as an 'educational arm', setting standards for acupuncture education through a formal process of approval (Saks, 1999). The formalization process was further enhanced in 1995 with the formation of the BACC, the leading self-regulatory body for the practice of traditional acupuncture in the UK (British Acupuncture Council, n.d.). From the mid-1990s, CAM courses, including acupuncture, started appearing in, or became accredited by, Higher Education Institutions (HEIs) in the UK (Isbell, 2004). Between 1995 and 2009 the number of CAM BSc, BA and MA level courses delivered or accredited by British universities grew dramatically from 4 to 44 courses (The Prince's Foundation for Integrated Care, 2009). The number of undergraduate acupuncture courses reached ten at its peak in 2009, while for the academic year 2014/15 eight such courses were on offer (of which three were not recruiting new students).

The 'mainstreaming' of acupuncture courses in Britain triggered two main concerns among practitioners. Firstly, that the increased formality, standardization and codification of traditional acupuncture knowledge will limit the indeterminacy and 'artistic interpretive autonomy' that is inherent in their practice (Clarke et al., 2004; Givati, 2015; Hirschkorn, 2006). And Secondly, often confused with the first, that the infusion of biomedical sciences into the curriculum and the growing emphasis on scientific investigation and RCTs - while it may enhance the scientific standing of CAM - 'lowers' or compromises practitioners' holistic discourses and holistic claims (Cant \& Sharma, 1998; Clarke et al., 2004; Jackson and Scambler, 2007). 
Such concerns are shared by other allied to medicine and social care professional groups. For example, the rise of the evidence base movement in the early 1990s and the codification of practice through clinical guidelines were perceived by many practitioners from within the medical professions and social care as a threat to the indeterminacy of professional practice (Timmermans and Mauck, 2005; Traynor, 2009; Webb, 2001). However, acupuncturists' engagement with the regulation and the formalization of their education is particularly intriguing for several reasons. First, in light of the tension that exists around practitioners' holistic/anti-reductionist discourses and claims which are now being contested in a process of 'mainstreaming' and of 'biomedical alignment'; second, in the context of the claim for epistemic authority (Gieryn, 1983) and the potential legitimization of acupuncture 'as a scientific discipline' within the walls of HEls; third, in relation to the context-specific, and the ever-present, impact of cultural, political and societal forces on the development of acupuncture practice (Barnes, 2003; Bivins, 2001; Scheid, 2002).

\section{Methods}

Data collection

The findings described here are part of a larger study exploring the way traditional acupuncturists and non-medically qualified (NMQ) homeopaths in the UK, in their efforts to professionalize and formalize their educational structure, negotiate holistic concepts that are embedded in their theory, practices and discourses. Data was gathered using an in-depth, qualitative approach, drawing on a number of data sets: 
(a) participant observation of teaching in a university-validated, BAcC-accredited BSc (Hons) acupuncture programme in South of England;, (b) in-depth interviews with thirteen active traditional acupuncture practitioners, including three heads of schools, six senior lecturers, and four graduates; and (c) textual analysis of BAcC accredited, university-validated, acupuncture courses' syllabi, as well as educational documents published by the professional body, the BAcC and its accreditation arm, the BAAB.

The utilisation of several data-collection tools offers a multifaceted view of the nuances of practitioners' social reality (Hesse-Biber, 2010), eliciting 'deeper and more genuine expressions of beliefs and values that emerge through dialogue [and] foster a more accurate description of views held' (Howe, 2004, p. 54). Furthermore, it allows for a rich description of participants' points of view and with it an opportunity to triangulate data and enhance generalizability of findings (Polit and Beck, 2010).

\section{Ethical approval}

Ethical approval for this research study was first obtained from the Departmental Ethics Committee at the University (granted in August, 2007), and later, for conducting the interviews, from the NHS National Research Ethics Service (NRES) (granted 22nd February, 2009). NRES approval was sought as part of a broader research project to allow the interviewing of practitioners who also practice in the NHS. Participants' anonymity was safeguarded and all interviews were based on the informed consent of participants. All names used in this paper are pseudonyms and 
the names of acupuncture schools are omitted. Moreover, in relation to online information from practitioners' websites, no direct quotes are used in this paper, unless rephrased, to avoid linking such online information to individual practitioners.

In-depth interviews

Thirteen active practitioners of traditional acupuncture, all members of the BAcC, were interviewed. Nine were acupuncture lecturers of whom three were heads of a university-validated programme. All three were directly engaged in guiding and negotiating the validation process and the professionalization effort of traditional acupuncturists in Britain. The four 'non-educators' participants were graduates of an accredited ('formalized') acupuncture course in Britain, providing a useful retrospective reflection on the formalization of their courses and on their motivation for enrolling to such course.

Interviews took place between 2008 and 2010. Practitioners were approached via email address obtained from the BAcC practitioner database. All participants were members of the BAcC and based in London and the south of England. All participants practised in a private setting. Two practised both privately and in an NHS setting. Practice experience was diverse, from one to thirty years. Eight of the practitioners were female and five male. Whilst all of the participants practised traditional (as opposed to medical) acupuncture, the sample included one participant who was also an MD (psychiatry), another who was a veterinary doctor, two who had 
a nursing qualification and one who was a senior biomedical researcher (immunology). This reflects the traditional acupuncture 'practice-scene' in Britain whereby it is not uncommon to find medically trained who choose to practice traditional rather than the medical (western) acupuncture (Bishop, Zaman, \& Lewith, 2011).

The interviews lasted between one and two hours. During the interview, practitioners were invited to openly discuss key challenges to acupuncture training and education from their perspective as school principals, educators or graduates. All interviews were audio-recorded and transcribed verbatim, and then sent back to interviewees to check for accuracy.

Participant observation

Participant observation in a university-validated acupuncture programme within a private Chinese medicine school in South of England provided valuable insight into the way in which the process of formalizing acupuncture education, the introduction of academic benchmark, and the challenges that are part of this process are negotiated by students and educators. Participant observation is particularly valuable in providing a window to meanings and interactions from the perspective of participants in an investigation that is flexible and open-ended in nature, often alongside other qualitative data collection instruments (Jorgensen, 1989). This allows for triangulation, increased depth and enhanced transferability of the findings (Pollit and Beck, 2010). Data was collected during the teaching of the Dissertation 
unit, a part of the final year of the course during which students developed, presented and submitted their final research project.

The lead researcher attended the college one day a month during the academic year 2008, joining the academic team as a temporary member of staff, attending staff meetings, supervising students' final year BSc dissertations, marking students' dissertations and marking oral presentations of their research projects. Access to this participant observation was granted by the school principal and by the unit coordinator. Students were verbally informed of the researcher's presence and of the process of collecting observational data, and, having been given the opportunity, did not object. Throughout the observation the confidentiality of students and staff at the school was maintained. No directs quotes are used from students' work, written or orally-presented.

In addition to the participant observation, in-depth interviews were conducted with the head of school, the unit coordinator, the clinical coordinator, and another senior lecturer on the unit. Data, whether personal reflections, students' work (written and oral), or information noted during staff meetings and tutorials with students, were placed and considered alongside data from in-depth interviews and textual analysis.

Textual analysis

Two forms of textual information informed this investigation. First, the British Acupuncture Council and its educational arm, the British Acupuncture Accreditation Board, provide online access to formal educational guidelines and accreditation 
requirements that each of the validated schools is expected to adhere to. These documents help understand the negotiation of the formalization process at the level

of the occupational leadership. A second source of information is acupuncture courses' syllabi and accredited schools' online information. Websites of the entire (2012) BAcC accreditation list, including courses' syllabi, were reviewed. This textual information provides an insight into the schools' adaptation strategies within the formalization process, the negotiation process of the school's adherence to 'formality', 'standardization' and 'biomedical alignment', and the projection of these developments in acupuncture education to 'the outside world'.

\section{Data analysis}

The data were analysed on the base of qualitative data analysis (QCA) (Mayring, 2000), including interview data and documents (Bauer, 2000, cited in Flick, 2006, p. 312). In this method the text is systematically read through and reduced in relation to the research questions and the remaining text is then examined in the context of key categories deriving from the theoretical models that drive the research ('contextual units'). Against this criterion the material is worked through and themes are developed inductively. During the development of themes, the validity of the guiding key categories are re-examined and updated. The guiding key conceptual categories were 'reference to holism as 'wider self' and as 'wider world"; 'regulating and standardizing acupuncture knowledge'; 'increased HEls involvement in acupuncture knowledge transmission'; 'maintaining practitioners' interpretive autonomy over expert knowledge'; and 'emphasising technicality or indeterminacy in knowledge transmission'. Hence, rather than starting the research with a (deductive) hypothesis 
that is to be proven or disproven, QCA identifies key categories from the literature and from theoretical models and then turns to the data to consider how these categories or terms are manifested in the data. Furthermore, although QCA was primarily used to analyse data that was gathered from interviews and textual material, key categories were used to contextualise, consider side-by-side, and synthesise all of our data sets.

Standardizing art and the art of standardizing - formalizing the teaching and practice of qi

Efforts to formalize and standardize acupuncture education involve a number of significant challenges on several levels. We have discussed the diverse nature of acupuncture theory and practice and the challenge to establish standardized knowledge that each acupuncturist should obtain upon graduation. Another challenge and is posed by 'externals' outside the practice environment. While biomedical alignment is commonly mentioned in relation to CAM practitioners' concerns over their holistic and esoteric claims, some scientists and academics outside the CAM circles actively oppose the teaching of acupuncture as an academic discipline within HEls, centring their critique over 'the unscientific and non-academic nature' of acupuncture (Colquhoun, 2008, one example out of very many). Paradoxically, central to both camps' concerns is the intangible, non-standardized nature of qi, the ungraspable vital force common to all acupuncture modalities, which does not correspond with biomedical concepts (Barnes, 2003). 
The document Guidelines for Acupuncture Education (2000) was published by the BAcC for those schools and courses in the UK working towards accreditation as well as schools that already obtained such accreditation, cementing commitment to HE standards in acupuncture education. Some of the professional values listed in the document demonstrate the highly indeterminate, artistic nature of acupuncture practice, including being 'holistic', 'compassionate', 'creative' and 'dynamic', and the importance of

Rhythm, flow, balance, harmony and resonance and the ways that changes in seasons and cycles of life inform both diagnosis and treatment (section 2).

Similarly, the Standards of Education and Training for Acupuncture (2011) that updated the previous guidelines indicates that students should be able to collect information on 'all aspects of the patient, body-mind-spirit', while mastering artistic skills including, among others, diagnosing the quality of the patient's radial pulses. For example the pulse can be diagnosed as 'floating', 'sinking', 'hesitant', 'slippery', each indicating a different state of qi imbalance. The artistic nature of pulse diagnosis is reflected in the way many current Chinese medicine doctors in China, seeing themselves as scientists, downgrade the importance of this skill or disregard it altogether (Scheid, 2002). This tension between acupuncture as an art and the desire to regulate and standardize it is part of the therapy's history. In reviewing Chinese medical texts 1840-1935, Scheid (ibid) discusses the concept of $y i$ as the

...physician's ability to grasp the ever-changing (bian) transformation of illness in clinical practice that lie beyond the regular (chang) manifestations described in books. It also signals the difficulty through the medium of language... [to capture what] we nowadays refer to as implicit and link to artistry and craft (Scheid, 2002, p.142). 
Graduates from undergraduate acupuncture courses discussed the esoteric nature of 'stems and branches' acupuncture and 'constitutional five elements' acupuncture as well as the difficult-to-capture nature of it. Chris, for example, who studied 'five elements' acupuncture commented:

I was quite uncomfortable with some of the approaches in Five Elements acupuncture training. In some ways I felt that the skill is too highly tuned, too subjective. You know, for example, we would be looking at facial expression during a single moment at a given time and I thought that it is just getting a little bit too difficult to interpret to be accurate.

It is not surprising, therefore, that the $\mathrm{BAcC}$ accreditation guidelines avoided indicating a process of codification for the manipulation of qi even though skills that are listed as core competencies include 'harmonising qi', 'treat emptiness [of $q$ ]] with tonification [of $q i$ and access [of $q i$ ]ith reduction [of $q i]$ ', feel and manipulate $q i$, directing qi, projection of $q i$, and 'maintenance of own $q i$ '.

Indeed, many CAM practitioners argue that their practice is artistic in nature, drawing on 'a kind of indeterminate, situated knowledge gained through experience: a form of craft knowledge inherently resistant to codification' (Clarke et al., 2004, p.335). Marylin, a former conventional doctor who now runs a busy acupuncture practice and is a senior lecturer in one of the BSc (Hons) acupuncture programmes discussed the intuitive nature of her practice:

I want to use my senses and my intuition [our emphasis] and I want to combine Stems and Branches. I would also like to combine energy. Also there are 400 acupuncture points. So if I use all of that I can get countless possibilities and only one will fit one particular individual.... 
The concept of indeterminacy in relation to medical practice was discussed by the French sociologists Jamous and Pelloile (1970) who suggested that professional work can be seen as a mixture of technical activities and indeterminate judgement, which they expressed as a ratio between the two (I/T ratio). The technical $(T)$ knowledge are the techniques and transmissible rules, described as 'the part played in the production process by "means" that can be mastered and communicated in the form of rules' (Jamous \& Peloille, 1970, p.112). Indeterminacy (I) are qualities of producers of professional skills, and, in the context of medical care, it is 'the clinician's emphasised individual and social potentialities, experience, talent, intuition, etc.' (ibid, p.139). By emphasising tacit or private knowledge, a high I/T ratio enables members of a profession to claim professional judgement and place their actions and decisions beyond the scrutiny of the lay public (Macdonald, 1995, p.165). The risk of such emphasis on indeterminacy is that in the absence of the ability to make codified predictions, other 'external' groups can make similar claims and the professional group may lose control over the field of practice (Traynor, 2009). Maintaining a high $\mathrm{I} / \mathrm{T}$ ratio is not unique to acupuncture and is arguably present in all professional practice. However, this concept is useful in highlighting the tensions that are part of the desire to formalize a group of practitioners who have been, for many years, working to establish their 'informal', 'non-mainstream' (i.e. alternative) position, a process which was accentuated during the teaching of acupuncture courses in HEls.

The schools: do we really witness a narrowing of the holistic view? 
Studies on professionalization highlighted the role of credentialism and educational institutions in the shift from an occupation to a profession (Macdonald, 1995). In the context of social closure, a university system provides a formal educational basis and systemic entry requirements which, in turn, allows the production and maintenance of a body of esoteric knowledge that requires considerable interpretation in its application (Larson, 1980). In relation to CAM, Cant and Sharma (1998) argue that the shift from a 'charismatic' teaching and apprenticeship model to more formal knowledge transmission structures, involved increased scientific rhetoric in the public presentation of knowledge, an alignment with the biomedical paradigm, and the dropping of esoteric knowledge claims. This raises questions about the role of HEls in the regulation of acupuncture in Britain, and the position of school leaders, once passionate counter-cultural proponents, who lead and negotiated the regulation process 'on the ground'. We suggest that the internal challenge of practitioners' fear that the formalization process bears more losses than gains is mostly part of the past. However, we present a more recent, 'external', challenge, that of scientists' and academics' opposition to the teaching of acupuncture in HEls.

To a certain degree it is possible to consider BAcC accredited schools' and courses' adherence to HE standards and criteria as strategic, pragmatic yet reluctant in nature, accepting an increased external scrutiny and with it losing their interpretive and diagnostic autonomy and lowering their 'holistic expression', in order to enhance their professional status. Nowadays, all of the school emphasise the BAcC accreditation and university validation of their courses on their websites, using it as a 'signature' for high-quality acupuncture education. The following quotes from school 
principals and the subsequent quote from a school website demonstrate their supportive view of the process.

Lisa, Nicola and Jeannette are the school principals of three leading acupuncture schools. All three schools were amongst the first to obtain university validation. During their interviews all three discussed their anxieties with about the regulation of their courses, yet all three perceived the fear of 'losing their holism' and 'losing the true nature' of traditional acupuncture as a worry of the past:

When we started with the accreditation process I thought we were sending ourselves down the drain. But l've never lost sight of our way and where the college should go (Nicola).

The big challenge was to keep the true nature of the course and the important parts of the course and at the same time make sure that we brought in everything that was needed for a degree level course. We have crossed that bridge a long time ago now and everything is kind of smooth with that (Jeannette).

Despite concerns that biomedical research, and in particular RCTs, are not suited to capture the non-standardized nature of traditional acupuncture, most of the accredited schools prompt practitioners and students to engage in research and promote research that will 'truly reflect' acupuncture practice. For example, one of the schools stated on its website:

We believe that acupuncturists need to engage with research [...] we must, as a profession, seek to produce research - and disseminate it - that better informs both our practice and external stakeholders. If we bury our heads in the sand or shake our heads from the side lines, poor quality and irrelevant research will continue to be carried out in our name. 
However, whilst the professional and educational leadership of traditional acupuncturists in Britain appears to have successfully negotiated some of the challenges, the 'rise' of CAM, and in particular acupuncture, in HEls prompted a significant criticism from influential 'externals'. In recent years the inclusion of BSc CAM courses in British academia was under concerted criticism from several highprofile academics, attacking the therapies' lack of scientific basis and 'academic nature' (Corbyn, 2008). Amongst the titles appearing in the popular media one would find language such as 'regulating quack medicine makes me feel sick' (Colquhoun, 2008), or 'Shamed: Universities offering bogus degrees in alternative medicine' (The Daily Mail Online, 2008). Such critique can be viewed in the context of boundary work (Gieryn, 1983), as scientists' fear that the 'legitimation' of CAM therapies by HEls would dilute their epistemic authority. This occurs in the way scientists attribute certain qualities to science, which are then used to demarcate between science and non-science and distinguish scientists from the less authoritative non-scientists by establishing their epistemic authority. In the context of Jamous and Pelloile's (1970) work, this assault on acupuncture demonstrates the risk whereby the inability to codify and standardize professional knowledge 'invites' interference by 'external' groups, leaving the newly emerging profession exposed to attacks. Asked to submit teaching and educational material for review (under the freedom of Information Act 2000), this external intervention against acupuncture was perceived by the three school principals as a real threat to the future of their courses in HEls.

Nevertheless, despite this campaign against undergraduate CAM courses, several BSc acupuncture courses are still being taught within British universities in faculties 
and departments such as Science \& Technology, Health \& Education, Health, Psychology and Social Care and Allied Health Sciences, alongside allied health professions including nursing, midwifery, physiotherapy, radiography, psychology, social work, mental health and sport science. There are signs that the teaching of acupuncture alongside mainstream health and social care disciplines in fact contributes to a broadening of traditional acupuncturists' holistic narrative, providing students with an increased awareness of social, cultural, political and environmental influences on individuals' and communities' well-being. The 2013 course accreditation guidelines includes an explicit expectation that accredited courses will

...provide evidence of how students are equipped to understand the political, social and economic aspects of the provision of acupuncture within the wider framework of healthcare in the UK (British Acupuncture Accreditation Board, 2013, p.30).

Acupuncture courses, in particular the university-based ones, now include units which suggest growing engagement with other healthcare disciplines and with public health concerns. Examples of such units are 'concepts of inter-professional practice in health and social care', 'the sociology of health', 'social research methods' or 'health psychology'. At the same time, despite the aforementioned 'campaign' against CAM courses, there is some evidence of a more CAM-welcoming approach from within academically-based allied health disciplines such as Public Health and Health Promotion (Hill, 2003), nursing and midwifery (Cant, Watts, \& Ruston, 2011) and physiotherapy (Givati, 2012). It is, therefore, possible that a 'cross-pollination' is taking place between traditional acupuncturists and other 'mainstream' health and social care disciplines. 
Notes from a participant observation during the final year of a BSc (hons) acupuncture

In this final section of our findings we would like to turn our attention to the perspective of staff and students who negotiate the formalization process 'on the ground'. The following notes from a participant observation of teaching during a BSc (Hons) acupuncture course in England present a number of 'snapshots' and impressions in relation to the uncertainty faced by both students and lecturers when simultaneously negotiating the increased biomedical alignment and the maintenance of the core Chinese medicine philosophy.

Two 'charismatic teachers' founded the acupuncture school in the early 1990s. In their first year they had just eight students and the school had no premises of its own. Three years later the management of the school was taken over by the current principal. Since then the college has grown, reaching a total of approximately 400 students. The college is housed in a modern building at a high street location. The acupuncture course is the main, but not the only, course at the school. Other courses are oriental herbal medicine, tui na, ${ }^{1}$ qi gong, ${ }^{2}$ and nutrition. In the late 1990s, the acupuncture course was accredited by the BAAB and several years later the course was university-validated as BSc (Hons) Acupuncture.

\footnotetext{
${ }^{1}$ Manual therapy that is guided by Chinese medicine

${ }^{2}$ A system of gentle movement and breathing exercises to promote the flow of qi
} 
The Dissertation unit

The observation took place during the teaching of the Dissertation unit, which was a 30 credit, final year (FHEQ level 6) module, part of a three-year full time BSc (hons) Acupuncture. During the unit students acquired introductory knowledge in biomedical research, including various research methodologies. Students conducted a systematic literature review of published medical research on acupuncture in the treatment of a certain health condition while also discussing the theoretical and clinical approach from a traditional acupuncture viewpoint. As part of the unit, students were required to formulate a research question, develop a project plan, identify suitable published research and appraise it according to the academic standards set by the validating university. Whilst on the unit students were introduced to basic quantitative concepts such as 'reliability', 'validity', 'bias', 'error', 'power' and 'standard deviation'.

Dissertation topics identified by students were mostly of a clinical nature. Examples include: 'Is traditional acupuncture as effective as western interventions in the alleviation of the pain experienced in fibromyalgia syndrome?' and 'Acupuncture in the treatment of postpartum depression'. The task of discussing both traditional acupuncture and biomedical perspectives posed a significant challenge, which Lisa, the school principal, captured in her interview: 
It is a bit like trying to learn a foreign language. You struggle and struggle and it won't lend itself to rational analysis. [...] If you want the students to look at a different life philosophy, you need to get them to question their own life philosophy [...] and that's an extremely uncomfortable place to sit in.

As part of the assessment strategy students were required to give a 10-minute presentation of their project and present the main findings. The atmosphere during the presentation event was strikingly informal. Some presented while sitting casually on a desk. A number of students rested their legs on the chair in front of them, cracking jokes with one another during presentations. During presentations presenters tended to adopt a negative view of conventional medicine, often referring to acupuncture as 'us' and to biomedicine (research and practice) as 'them'. Biomedicine was often referred to as 'short-sighted', 'reductionist', 'unsuccessfu', and 'aggressive'. This observation was confirmed during interviews with lecturers on the course, expressing frustration with students' perpetuation of 'anti-biomedical' notions, something that staff claimed to discourage. In contrast, no critical comments were made in relation to acupuncture practice. Furthermore, students often employed Chinese medicine textbooks written by known teachers as unchallenged evidence for the benefits of acupuncture. For example, the well-known textbook The Foundation of Chinese Medicine by Giovanni Maciocia that is based on historical texts and accumulated practice experience was often cited by presenters as a form of 'decisive' evidence in support of the effectiveness of acupuncture in clinical conditions.

At the end of each presentation one of the two assessors posed a question in relation to the presented material. This appeared to take some students by surprise, 
despite the non-confrontational manner of the questions. Following half a dozen presentations, a number of students protested that being asked questions put them in a state of distress. The following day an email from the unit coordinator reminded staff to avoid posing questions during students' presentations.

It is possible that students' 'casual behaviour' during the presentation, the protest made over academic scrutiny during their presentations, and the school's response to the protest, reflect a certain objection to the formalization process whereby practitioners find themselves having to adhere to a 'mainstream educational system', increasingly mirroring biomedical education (Barnes, 2003). It is also very likely that what we have observed reflects a gap in 'formality' between the private universityvalidated schools and the university-based acupuncture courses in spite of the standardization process. Certainly such observations require further investigation.

It is suggested that $I / T$ ratio is being pragmatically 'expanded' or 'reduced' by students on the course according to circumstances. On the one hand, during both presentation events, students made frequent and often in-depth reference to biomedical concepts from the fields of human biology, anatomy and physiology, pharmacology and other biomedical sciences. One student described the coagulation cascade and the morphology of red blood cells, while another described in detail the physiological impact of electrolyte imbalances in uncontrolled vomiting during pregnancy. Despite this common reliance on biomedical knowledge there was clear a-symmetric application of criticality towards biomedicine and a lack of criticality towards Chinese medicine theory. On several occasions, students rejected 
findings from RCTs if they did not support acupuncture treatment, pointing at the incompetency of clinical trials to capture acupuncture's individualized, holistic nature.

In contrast, students very often welcomed biomedical evidence when it did support acupuncture's effectiveness or safety. While these observations are limited and it is certainly possible to argue that two cohorts at the same school are not necessarily representative of other settings, they do provide a sense of the uncertain and often ambiguous position that both staff and students in a 'formalized' acupuncture course grapple with. Students and staff appear to have ambivalent feelings regarding the degree of formality that is applied in order to obtain an undergraduate degree, and the desire to maintain a sense of homeliness and informality as part of the teaching and learning experience. Perhaps more striking is that the increased biomedical alignment and the emphasis on EBP poses students with a dilemma, whether to 'give in' to biomedical authority and use it when possible to promote the credibility of their practice, or to reject it as 'guardians of the purity of acupuncture'.

Whatever the challenges faced by students and staff, we can certainly support the observation that acupuncture schools are 'much more than passive transmitters of knowledge and skills' (Flesh, 2013, p.18). Rather, through their efforts to negotiate and 'resolve' tensions between 'scientific' and 'esoteric' knowledge, and between 'mainstream' and 'marginality', they are engaged in in a dynamic and reflexive process of (re)shaping their professional knowledge.

\section{Concluding Discussion}


While considering holism as a negotiable, situated concept, this article has emphasised the non-essentialized and context-specific nature of acupuncture practice, and discussed the formalization of acupuncture training in Britain as a process of ongoing negotiation of contemporary political, cultural and societal forces. We have attempted to use several lenses. In respect to the perspective of the 'storytellers', we presented the views of practitioners, students, educators, 'schools' and the professional organization. Methodologically, we used interchangeably both a more 'distant' data- analysis approach (textual analysis) as well as a more 'intimate' perspective through participant observation. By doing so we have experienced the process of formalizing acupuncture education as a dynamic process of negotiation between pragmatic and ideological notions whereby 'professionalization has coincided with cultural translations of the modality [....] motivated not only by a desire for status but also by an ideological commitment' (Barnes, 2003, p.296). Indeed, this process of negotiation is pragmatic and adaptable, responsive to societal and cultural forces, but also, a source of change in itself. By the nature of their responses, narratives and strategies, practitioners play an important role in the shaping and defining their professional knowledge.

British acupuncturists appear to have conquered their concern of losing their holistic ideology and their theoretical orientation, and they have entered a process of renegotiation of their values as well as a re-evaluation of their views towards mainstream medical care, although, as evident by students' presentations, this process is still being contested. During her interview, Lisa, a school principal, commented: 
I don't think you can say that any change [i.e. academic validation] 'takes away' anything. I think you can say that 'it makes it difference'. Maybe bits of things are getting lost along the way and other things get added. But I am not scared of the process of change. I am not protectionist about Chinese medicine. I suppose I am too passionate about it to be a protectionist about it.

The conceptualization of formalizing acupuncture education as a strategy of mainstream inclusion (Witz, 1990), and with it the increasing standardization of esoteric knowledge and the lowering of $\mathrm{I} / \mathrm{T}$ ratio (Jamous and Pelloile, 1970), point at the more transparent and vulnerable position of the university-validated courses. However, whilst the direct benefits of regulation remain limited (Cant, 2009), acupuncturists' engagement with HEls can be seen as a spring for fruitful interaction with 'neighbouring' practitioners occupying health and social care practice in Britain today. Somewhat paradoxically, it appears to enhance the holistic narration beyond the narrow focus on individual behaviour and individual responsibility towards greater consideration of fundamental societal, economic and cultural influences on health. Therefore, as a whole, the challenges that acupuncture practitioners, educators and students grapple with during the processes of negotiating the seemingly incompatible Chinese medicine and biomedical concepts can be seen as offering the potential for introspective critical development and as an expansion of the scope of acupuncture practice rather than strictly a process of mere subordination to biomedical domination. 


\section{References}

Baer, H., Hays, J., McCLendon, N., McGoldrick, N., \& Vespucci, R. (1998). The holistic health movement in the San Francisco bay area: Some preliminary observations. Social Science \& Medicine, 47(10), 1495-1501.

Baer, H. (2003). The work of Andrew Weil and Deepak Chopra - two holistic health/New Age gurus: A critique of the holistic health/New Age movements. Medical Anthropology Quarterly, 17(2), 233-250. 
Barnes, L. (2003). The acupuncture wars: the professionalizing of American acupuncture--a view from Massachusetts. Medical Anthropology, 22(3):261301.

Barnes, L. (2005). American acupuncture and efficacy: meanings and their points of insertion. Medical Anthropology Quarterly, 19(3):239-66.

Bates, D. (2002). Why not call modern medicine 'alternative'? Annals of American Academy of Political and Social Sciences, 583(1), 12-28.

Bishop, F., Zaman, S., \& Lewith, G. (2011). Acupuncture for low back pain: A survey of clinical practice in the UK. Complementary Therapies in Medicine, 19(3), 144-148

Bivins, R. (2001). The needle and the Lancet: Acupuncture in Britain, 1683-2000. Acupuncture in Medicine, 19(1), 2-14.

British Acupuncture Accreditation Board. (2010). Accreditation handbook. London: British Acupuncture Accreditation Board.

British Acupuncture Council. (2000). Guidelines for Acupuncture Education. London: British Acupuncture Council.

British Acupuncture Council. (2011). Standards of Education and Training for Acupuncture. London: British Acupuncture Council

Cant, S. (2009). Mainstream marginality: 'Non-orthodox' medicine in an 'orthodox' health service. In J. Gabe and M. Calnan (Eds.), The new sociology of health service. London: Routledge.

Cant., S., \& Sharma, U. (1998). A new medical pluralism: complementary medicine, doctors, patients and the state. London: Routledge.

Cant, S., Watts, P., \& Ruston, A. (2011). Negotiating Competency, Professionalism and Risk: The Integration of Complementary and Alternative Medicine by Nurses and Midwives in NHS Hospitals. Social Science \& Medicine, 72(4), 529-36.

Clarke, B., Doel, A. \& Sergott, J. (2004). No alternative? The regulation and professionalization of complementary and alternative medicine in the United Kingdom. Health and Place, 10(4) 329-338.

Colquhoun, D. (2008, August 29). Regulating quack medicine makes me feel sick. The Times Online. Retrieved June 19, 2009, from http://www.timesonline.co.uk/tol/comment/columnists/guest contributors/article 4628938.ece

Connelly, D. (1979). Traditional Acupuncture: The Law of the Five Elements. The Centre for Traditional Acupuncture.

Corbyn, Z. (2008, October 30). Unwelcomed complements. The Times Higher Education [On line]. Retrieved from http://www.timeshighereducation.co.uk/story.asp?storycode=404104 
Crawford, R. (2006). Health as a meaningful social practice. Health, 10(4), 401-420.

Fadlon, J. (2004). Meridians, chakras, and psycho-neuro-immunology: the dematerializing body and the domestication of alternative medicine. Body \& Society, 10(4), 69-86.

Flesh, H., A foot in both worlds: education and transformation of Chinese medicine in the United States. Medical anthropology, 32(1):8-24.

Gale, N. (2014). The sociology of traditional, complementary and alternative medicine. Sociology Compass, 8(6), 805-822.

Givati, A. (2012). The Holistic Discourse and Formalising Education of Non-medically Qualified Acupuncturists and Homeopaths in England: an In-depth, Qualitative Study. Ph.D. thesis, University of Portsmouth.

Givati, A. (2015). 'pragmatic holism': professionalization and the holistic discourse of non-medically qualified acupuncturists and homeopaths in the UK. Health, 19(1), 34-50

Gieryn, T. (1983). Boundary-work and the demarcation of science from non-science: Strains and interests in professional ideologies of scientists. American Sociological Review, 48(6), 781-795.

Hasegawa, H., Reilly, D., Mercer, S., \& Bikker, A. (2005). Holism in primary care: The views of Scotland's general practitioners. Primary Health Care Research and Development, 6(4), 320-328.

Hesse-Biber, S. (2010). Qualitative Approaches to Mixed Methods Practice. Qualitative Inquiry, 16(6) 455-468.

Hill, F. (2003). Towards a new model for health promotion? An analysis of complementary and alternative medicine and models of health promotion. Health Education Journal, 62(4), 369-380.

Hirschkorn, K. (2006). Exclusive versus everyday forms of professional knowledge: Legitimacy claims in conventional and alternative medicine. Sociology of Health and IIIness, 28(5), 533-557.

Howe, K. R. (2004). A critique of experimentalism. Qualitative Inquiry, 10(1), 42-61.

Isbell, B. (2004). Finding the right complementary therapies course, Complementary Therapies in Nursing and Midwifery, 10(2), 92-96

Jackson, S., \& Scambler, G. (2007). Perceptions of evidence-based medicine: traditional acupuncturists in the UK and resistance to biomedical models of evaluation. Sociology of Health \& IIIness, 29(3), 412-429.

Jamous, H., \& Peloille, B. (1970). Changes in the French university-hospital system. In Jackson, J.A. (Ed.), Professions and Professionalization. Cambridge: Cambridge University Press.

Jorgensen, D. (1989). Participant observation: A methodology of human studies. London: Sage. 
Kelner, M., Wellman, B., Welsh, S., \& Boon, H. (2006). How far can complementary and alternative medicine go? The case of chiropractic and homeopathy. Social Science \& Medicine, 63(10), 2617-2627.

Keshet, Y. (2009). The untenable boundaries of biomedical knowledge: epistemologies and rhetoric strategies in the debate over evaluating complementary and alternative medicine. Health, 13(2), 131-155.

Larson, M.S. (1980). Proletarianization and educated labour. Theory and Society, $9(1), 131-175$

Lawrence, C. and Weisz, G. (1998) Greater than the parts: holism in biomedicine, 1920-1950. Oxford: Oxford University Press.

Lowenberg, J., \& Davis, F. (1994). Beyond medicalisation-demedicalisation: The case of holistic health. Sociology of Health and IIIness, 16(5), 579-599.

Mayring, P. (2000). Qualitative content analysis. FQS Forum, Qualitative Social Research Sozialforschung, 1(2).

Macdonald, K. (1995). The sociology of the professions. London: Sage.

Montgomery, S. (1993). Illness and Image in Holistic Discourse. Cultural Critique, 25, 65-89.

Rosenberg, C. (1998) Holism in twentieth-century medicine. In C. Lawrence and G. Weisz (Eds.), Greater than the parts: holism in biomedicine, 1920-1950. Oxford: Oxford University Press.

Shahjahan, R., (2004). Standards of education, regulation and market control: perspectives on complementary and alternative medicine in Ontario, Canada. Journal of Alternative and Complementary Medicine. 10(2): p. 409-412.

Saks, M. (1999). The wheel turns? Professionalisation and alternative medicine in Britain. Journal of Interprofessional Care, 13(2), 129-138.

Saks, M. (2001). Alternative medicine and the health care division of labour: present trends and future prospects. Current Sociology, 49(3), 119-134.

Scheid, V. (2002). Remodeling the Arsenal of Chinese Medicine: Shared Pasts, Alternative Futures. The ANNALS of the American Academy of Political and Social Science, 583(1), 136-159.

Scott, A. (1999) Paradoxes of holism: Some problems in developing an antioppressive medical practice. Health, 3(2), 131-149. Shuval, J., \& Averbuch, E. (2012). Alternative and Bio-Medicine in Israel: Boundaries and Bridges. Brighton: Academic Studies Press.

Timmermans, S., \& Mauck, A. (2005). The promises and pitfalls of evidence-based medicine. Health Affairs, 24(1), 18-28.

The Daily Mail Online. (2008, April 23). Shamed: Universities offering 'bogus' degrees in alternative medicine. The Daily Mail Online. Retrieved from 
http://www.dailymail.co.uk/news/article-1016640/Shamed-Universities-offeringbogus-degrees-alternative-medicine.html

The Prince's Foundation for Integrated Health. (2009). HE Accredited Courses in Complementary Healthcare 2009. Retrieved from http://www.fih.org.uk/information library/publications/health guidelines/he accr edited.html

Webb, S. (2001). Some Considerations on the Validity of Evidence -based Practice in Social Work. British Journal of Social Work, 31(1), 57-79.

Welsh, S., Kelner, M., Wellman, B., \& Boon, H. (2004). Moving forward?

Complementary and alternative practitioners seeking self regulation. Sociology of Health and IIIness, 26(2), 216-241.

Witz, A. (1992). Professions and Patriarchy. London: Routledge. 